\title{
Opportunities to train small-scale goat farmers within on-farm research projects
}

\author{
A. F. Vatta ${ }^{1 \dagger}$, J. F. de Villiers ${ }^{2}$, L. J. S. Harrison ${ }^{3}$, R. C. Krecek ${ }^{1,4}$, R. A. Pearson ${ }^{3}$, \\ F. H. J. Rijkenberg ${ }^{5}$, A. Spickett ${ }^{6}$ and S. H. Worth ${ }^{5}$
}

\begin{abstract}
${ }^{1}$ Ross University School of Veterinary Medicine, P.O. Box 334, Basseterre, St Kitts, St Kitts and Nevis, West Indies; ${ }^{2}$ KwaZulu-Natal Department of Agriculture, Environmental Affairs and Rural Development, Private Bag X6005, Hilton, 3245, South Africa; ${ }^{3}$ University of Edinburgh, Royal (Dick) School of Veterinary Studies, Division of Veterinary Clinical Science, Easter Bush Veterinary Centre, Easter Bush, Roslin, Midlothian, EH25 9RG, United Kingdom; ${ }^{4}$ University of Johannesburg, Auckland Park, 2006, South Africa; ${ }^{5}$ University of KwaZulu-Natal, Private Bag X01, Scottsville, 3209, South Africa; ${ }^{6}$ Onderstepoort Veterinary Institute, Private Bag X05, Onderstepoort, 0110, South Africa
\end{abstract}

\section{Introduction}

A number of studies were conducted in KwaZulu-Natal Province, South Africa over a 10-year period (1998 to 2008), involving on-farm research and extension and small-scale goat farmers (Vatta et al., 2001, 2007; Spickett, 2009). The general aim was to ameliorate the various problems affecting the health and productivity of goats in these communities. These included diarrhoea, gastro-intestinal nematode infection and poor reproductive performance.

\section{Materials and methods}

The purpose of this paper is to examine how the process of engagement with the individual farmers was initiated and maintained for the purposes of carrying out on-farm research projects, and how the results of the projects as well as general animal health were disseminated more widely within the community. The paper compares three projects which were conducted subsequent to one another over periods of 12-21 months each in the communities of Impendle, Bulwer and Bergville. The degree to which the participatory approaches helped increase the communities' awareness of and ability to deal with goat health and management problems was assessed in the Bulwer project through questionnaire surveys conducted with participating and non-participating farmers and the general community.

\section{Results}

Initially, 2 farmers in the Impendle region took part, followed by 9 farmers in Bulwer and latterly, 15 farmers in Bergville. A key factor in the success of the projects in Bulwer and Bergville in engaging the farmers and their communities, when compared with the Impendle project, was the development of a flexible framework for the acquisition of skills and knowledge, which included the use of the on-farm research project as a training vehicle. The farmers were trained in basic health care techniques such as drenching, injections, hoof trimming and the use of the FAMACHA system, a simple method for diagnosing anaemia, a sign of gastrointestinal nematode infection. A "Goatkeepers' Animal Health Care Manual" and other extension materials were developed. Workshops within the communities were used to strengthen the farmers' knowledge of animal diseases and their treatment. Participating farmers in the Bulwer project indicated that their goats had showed an improved rate of kidding, an improved survival rate for goat kids and increases in the total numbers of goats - an indication of improvement of the reproductive performance of the goats. Promulgation of the information and skills nurtured "champions" in the local farming community. These farmer "champions" constituted important role models and a local source of advice and encouragement for other farmers. Other factors that were important in the success of especially the latter projects were the use of "hands-on" approaches, thorough preparatory phases, regular meetings with the farmers geared to their levels of expertise, and effective collaboration between the institutions of teaching, research and extension and the farmers.

\section{Conclusions}

On-farm research projects present ideal opportunities to facilitate the acquisition of skills and knowledge by small-scale farmers, and to provide insight for the researcher into the community for whom the research is aimed. The flexible framework developed as part of three very successful studies described here may be equally applied to assist farmers in the Caribbean region.

\author{
References \\ Vatta AF, Letty BA, Van der Linde MJ, Van Wijk EF, Hansen JW and Krecek RC 2001. Veterinary Parasitology 99, 1-14. \\ Spickett A 2009. M.Sc. Dissertation, University of Pretoria.
}

\footnotetext{
${ }^{\dagger}$ E-mail: avatta@rossvet.edu.kn
} 